\title{
Selective killing of Aggregatibacter actinomycetemcomitans by ciprofloxacin during development of a dual species biofilm with Streptococcus sanguinis
}

\author{
Peter Suci ${ }^{a, b, *}$, Mark Young ${ }^{a, c}$ \\ ${ }^{a}$ Department of Plant Sciences, Montana State University, Bozeman 59717, MT, United States \\ ${ }^{\mathrm{b}}$ Center for Biofilm Engineering, Montana State University, Bozeman 59717, MT, United States \\ ${ }^{c}$ Department of Chemistry \& Biochemistry, Montana State University, Bozeman 59717, MT, United States
}

\section{A R T I C L E I N F O}

Article history:

Received 22 November 2010

Received in revised form

15 February 2011

Accepted 24 March 2011

\section{Keywords:}

Periodontal disease

Aggregatibacter

actinomycetmecomitans

Biofilm

Ciprofloxacin

Consortium

\begin{abstract}
A B S T R A C T
Objectives: Periodontal disease is associated with a pathogen-induced transition to a chronic destructive inflammatory response. Since commensals may either passively or actively contribute to immune homeostasis, therapies aimed at selectively reducing the competitive advantage of pathogens may be effective supplements to traditional methods. We developed an in vitro system to grow biofilms composed of the pathogen (Aggregatibacter actinomycetemcomitans) and the commensal (Streptococcus sanguinis). We used the biofilm model to determine the feasibility of selectively killing the pathogen using the fluoroquinolone, ciprofloxacin.

Design: Biofilms were exposed to relevant ciprofloxacin doses during the first $24 \mathrm{~h}$ of development, with subsequent removal of the ciprofloxacin for a $24 \mathrm{~h}$ period. Biofilm growth was assessed by confocal laser scanning microscopy, crystal violet staining and DNA abundance.

Results: Exposure to $0.01 \mathrm{mg} / \mathrm{L}$ or $0.5 \mathrm{mg} / \mathrm{L}$ ciprofloxacin significantly reduced the microcolony size and cell surface density of A. actinomycetemcomitans in the dual species biofilm over a $24 \mathrm{~h}$ period whilst allowing uninhibited S. sanguinis biofilm formation. A. actinomycetemcomitans biofilm development was insignificant over a subsequent $24 \mathrm{~h}$ period after removal of the ciprofloxacin indicating that A. actinomycetemcomitans cells were killed.

Conclusions: A. actinomycetemcomitans residing in a dual species biofilm with the commensal, S. sanguinis can be selectively killed, or at least rendered metabolically inactive, by treatment with ciprofloxacin. The dual species biofilm model will be a useful tool for designing in vivo studies to determine the efficacy of selective killing agents as an adjunct treatment of localized aggressive forms of periodontal disease.
\end{abstract}

(C) 2011 Elsevier Ltd. All rights reserved.

* Corresponding author at: Department of Plant Sciences, Montana State University, Bozeman 59717, MT, United States.

Tel.: +1 4069947219 .

E-mail address: peter_s@erc.montana.edu (P. Suci).

Abbreviations: anti-Aa Ab, monoclonal antibody against Aggregatibacter actinomycetemcomitans; CLSM, confocal laser scanning microscope; CV, crystal violet. 


\section{Introduction}

Diseases associated with chronic inflammation are amongst the most difficult to treat. ${ }^{1-3}$ In periodontal disease a cascade of events, triggered by changes in the oral microbial consortium, result in tissue and bone destruction that is orchestrated primarily by components of the immune system. ${ }^{4-6}$ This chronic immune response is both destructive and unproductive since it does not eliminate the pathogens. ${ }^{7}$

The oral cavity is similar to the gut in that it is colonized by a complex consortium of commensals in healthy individuals. ${ }^{8}$ Commensal microbes in the gut play an active role in passivating the inflammatory response to pathogens. ${ }^{9}$ It is likely that oral commensals play a significant role in maintaining immune homeostasis in the oral cavity. ${ }^{10}$ However, there is no direct evidence to support this claim.

Traditional methods of treatment of periodontal disease aim at removing or inactivating both pathogens and commensals indiscriminately. ${ }^{11}$ In contrast, in a healthy state, the immune system's management of the oral consortium likely involves targeted inactivation of low levels of pathogens by a productive acute inflammatory response, since the oral mucosal immune system responds selectively to pathogens. ${ }^{12,13}$ The implication is that selective killing of pathogens by antimicrobials could enhance or supplement normal immune function and mitigate the transition to a chronic inflammatory immune response. The key determining factor in restoring immune homeostasis by this strategy would be a reduction in the pathogen presence relative to that of the commensals, which might be achieved most effectively during the regrowth period after a conventional treatment.

Putative pathogens of periodontal disease are primarily gram-negative bacteria. ${ }^{14-16}$ This suggests that the appropriate dose of a fluoroquinolone might selectively target periodontal pathogens in a biofilm consortium, since fluoroquinolones are generally more efficacious against gramnegative bacteria than gram-positive bacteria. ${ }^{17,18}$ In particular the ciprofloxacin MICs for strains of the oral commensal Streptococcus sanguinis $(0.5-16 \mathrm{mg} / \mathrm{L})$ are substantially higher than the MICs for strains of Aggregatibacter actinomycetemcomitans (formerly Actinobacillus actinomycetemcomitans) (0.002$0.006 \mathrm{mg} / \mathrm{L}){ }^{19,20}$ the primary etiological agent of localized aggressive periodontitis. ${ }^{21,22}$ A possible caveat to this approach that can be addressed initially with in vitro systems is that the oral microbial population is primarily in the biofilm form ${ }^{16}$ and the biofilm mode of growth can affect the efficacy of antimicrobials in complex and indeterminate ways. ${ }^{23}$ In the case of oral biofilms, there is an additional possible complicating factor of the contribution of consortium interspecies interactions to antimicrobial efficacy.

In vitro multispecies oral biofilm model systems have been developed previously to investigate interspecies interactions, as well as the influence of antimicrobials and nutrients on the biofilm composition. ${ }^{24-27}$ Here, we developed an in vitro dual species biofilm model composed of A. actinomycetemcomitans and S. sanguinis to determine whether exposure to ciprofloxacin could be used to control the consortium composition. The biofilm model is a tool that can be used to aid in the rational design of in vivo experiments to test the hypothesis that selective killing of pathogens will enhance restoration of immune homeostasis.

\section{Methods}

\subsection{Bacterial strains and media}

A. actinomycetemcomitans strain D7S, a rough colony clinical isolate obtained from the central incisor of an African American female patient with generalized aggressive periodontitis was provided by Casey Chen, University of Southern California. S. sanguinis SK36, used previously for biofilm studies, ${ }^{28}$ was obtained from ATCC (BAA-1455). Media consisted of modified tryptic soy broth (MTSB) ${ }^{29}$ with $50 \mathrm{~mL}$ foetal bovine serum (HyClone) and 15 g bacto agar added (per litre) for solid medium, brain heart infusion broth (BHI) with $15 \mathrm{~g}$ bacto agar added (per litre) for solid medium, and a defined biofilm medium (BM) with $1 \%$ sucrose used previously to culture S. sanguinis biofilms. ${ }^{28}$ Frozen stocks were maintained at $-80{ }^{\circ} \mathrm{C}$ in $20 \%$ glycerol, $80 \%$ MTSB (A. actinomycetemcomitans) or BHI (S. sanguinis).

\subsection{Biofilm culturing}

All culturing was performed at $37{ }^{\circ} \mathrm{C}$ in $5 \% \mathrm{CO}_{2}$. Biofilms were cultured in 96 well polystyrene microtiter plates (Falcon Optilux $^{\mathrm{TM}}$, Fisher Scientific) in BM with $10 \%$ MTSB added. This medium was chosen on the basis of preliminary studies which indicated that $\mathrm{A}$. actinomycetemcomitans did not grow perceptibly in BM over a $48 \mathrm{~h}$ period. S. sanguinis biofilms did form in MTSB but the biofilms were so tenuously attached to the surface that a single rinse step would remove them. The A. actinomycetemcomitans biofilm inoculum was prepared by looping colonies, cultured on solid medium for $60 \mathrm{~h}$, into a $1 \mathrm{~mL}$ aliquot of liquid medium. This suspension of cell aggregates was dispersed by repeated pipetting followed by forcing the suspension through a small bore needle (25G 7/8, Becton Dickinson). This suspension, which still consisted of cell aggregates with a range of sizes, was then filtered through two $5 \mu \mathrm{m}$ pore filters (National Scientific Target Nylon Syringe Filter, $30 \mathrm{~mm}$, Fisher Scientific) in tandem and diluted into the biofilm medium to obtain approximately $10^{7} \mathrm{CFU} / \mathrm{mL}$ (based on an OD measurement). The $S$. sanguinis biofilm inoculum was prepared by inoculating $100 \mu \mathrm{L}$ of a $60 \mathrm{~h} 5 \mathrm{~mL}$ BHI broth culture started from a frozen stock into $5 \mathrm{~mL}$ fresh $\mathrm{BHI}$, incubating for $24 \mathrm{~h}$, adjusting the cell density to approximately $10^{8} \mathrm{CFU} / \mathrm{mL}$ (based on an OD measurement), and making a 1:1000 dilution of this cell suspension, either into biofilm medium (S. sanguinis single species biofilm inoculum) or into an aliquot of the A. actinomycetemcomitans biofilm inoculum (A. actinomycetemcomitans/S. sanguinis dual species biofilm inoculum), to obtain approximately $10^{5} \mathrm{CFU} / \mathrm{mL}$ in both cases. The biofilms were inoculated by filling each well with $100 \mu \mathrm{L}$ of the appropriate cell suspension (either pure A. actinomycetemcomitans, pure S. sanguinis or a mixture of A. actinomycetemcomitans and S. sanguinis) and incubating for $1 \mathrm{~h}$. The inoculum was then replaced by fresh medium $(200 \mu \mathrm{L})$ with or without ciprofloxacin. This medium was replaced at $24 \mathrm{~h}$ by fresh medium without ciprofloxacin $(200 \mu \mathrm{L})$ for biofilms cultured for $48 \mathrm{~h}$. 


\subsection{Antimicrobial treatment}

Biofilms were treated with ciprofloxacin by filling wells with a solution of ciprofloxacin in the culture medium and incubating under the culturing conditions for $24 \mathrm{~h}$. A $1 \mathrm{mg} / \mathrm{mL}$ ciprofloxacin solution was made from ciprofloxacin hydrochloride in methanol (ICN Biomedicals Inc. Catalogue \# 199020) and subsequently diluted to $20 \mathrm{mg} / \mathrm{L}$ in sterile nanopure water. Appropriate volumes of this solution were added to culture medium to obtain 0.01 and $0.5 \mathrm{mg} / \mathrm{L}$ solutions. These solutions were filtered through a $0.2 \mu \mathrm{m}$ filter before use.

\subsection{Biofilm visualization}

Confocal laser scanning microscope (CLSM) images were acquired with a Leica TCS-SP2-AOBS. Biofilm microcolonies were visualized through the floor of the wells by using a previous protocol. ${ }^{29}$ Images were collected with a $40 \times 0.8 \mathrm{NA}$ HCX APO L U-V-I water immersion objective. For CLSM visualization biofilms were labelled with an antibody specific for A. actinomycetemcomitans and a nucleic acid stain (SYTO 59, Invitrogen) that labels both $\mathrm{A}$. actinomycetemcomitans and $\mathrm{S}$. sanguinis. Monoclonal antibody (Aa-mAb) $225 \mathrm{AA} 2^{30}$ against $\mathrm{A}$. actinomycetemcomitans, isotype mIgG2b, was donated by Rudolf Gmür, University of Zürich and purified as described previously. ${ }^{29}$ The Aa-mAb 225AA2 epitope has been shown to be highly specific for A. actinomycetemcomitans. ${ }^{30}$ No detectable cross reaction of the Aa-mAb with $\mathrm{S}$. sanguinis planktonic cells was detected using a dot blot immunoassay, or with $\mathrm{S}$. sanguinis biofilm using CLSM. For staining, biofilms were first washed with 1\% BSA in $10 \mathrm{mM}$ PBS (pH 7.0, $100 \mathrm{mM} \mathrm{NaCl}$ ) for $5 \mathrm{~min}$. Biofilms were subsequently rinsed with $0.85 \%$ saline between each step. Antibody and nucleic acid stain were also prepared in $0.85 \%$ saline. Biofilms were exposed to $\mathrm{Aa}-\mathrm{mAb}$ at approximately $50 \mu \mathrm{g} / \mathrm{mL}$ for $50 \mathrm{~min}$ followed by exposure to a 1:100 dilution of fluorescently labelled secondary Ab (Alexa Fluor 488 rabbit antimouse IgG, Invitrogen) for $50 \mathrm{~min}$, and finally a $15 \mu \mathrm{M}$ SYTO 59 solution for $10 \mathrm{~min}$. Green fluorescence from the anti-mouse secondary antibody and red fluorescence from the SYTO 59 nucleic acid stain were discriminated using Acousto-optical tunable filters. ${ }^{29}$ Images were acquired at $2.0 \mu \mathrm{m}$ intervals throughout the depth of the biofilms. Stacks were combined in Imaris software (Bitplane AG, Zürich, Switzerland) to yield final images. A. actinomycetemcomitans colony biovolumes were determined using the Imaris volumetric analysis software add-on. ${ }^{26}$

\subsection{Crystal violet assay}

Biofilms were rinsed with PBS and then exposed to a 1:4 dilution of the crystal violet (CV) solution (Protocol Crystal Violet, Fisher Scientific) for $15 \mathrm{~min}$. This was followed by three rinses with nanopure water and addition of $200 \mu \mathrm{L}$ of ethanol to each well. After a $1 \mathrm{~h}$ incubation period each well was mixed by pipeting and 1:10 dilutions were made in separate wells to allow for absorbances above 1 . The absorbance of each well (including both diluted and undiluted wells) at $600 \mathrm{~nm}$ was then acquired using a plate reader. Values reported are estimates for undiluted wells containing $200 \mu \mathrm{L}$ of the solution with the background from a sterile well exposed to the same CV solution and rinses subtracted.

\subsection{Quantification of cell surface densities based on DNA abundance}

DNA was extracted from biofilms by first lysing the cells in situ in the microtiter wells and then isolating the DNA using a GenElute $^{\mathrm{TM}}$ Bacterial Genomic DNA kit (Sigma-Aldrich). Cells were lysed using a modification of a protocol designed for $\mathrm{S}$. sanguinis. ${ }^{31}$ Modifications were made to enhance lysis of the gram-negative A. actinomycetemcomitans. Wells were rinsed 3 times with $200 \mu \mathrm{L}$ of $20 \mathrm{mM}$ Tris, $5 \mathrm{mM}$ EDTA, $100 \mathrm{mM} \mathrm{NaCl}, \mathrm{pH}$ 7.0. Mutanolysin (Sigma-Aldrich, M9901) was added to obtain approximately $500 \mathrm{U} / \mathrm{mL}$ and the plate was incubated for $90 \mathrm{~min}$ at $37^{\circ} \mathrm{C}$. RNase (Sigma-Aldrich) was added to obtain a concentration of $0.5 \mathrm{mg} / \mathrm{mL}$ followed by addition of lysozyme (Fisher Scientific, BP535-1) to obtain a concentration of $2 \mathrm{mg} /$ $\mathrm{mL}$ and the plate was incubated for $45 \mathrm{~min}$ at $37^{\circ} \mathrm{C}$. Proteinase $\mathrm{K}$ (Sigma-Aldrich, P2308) was added to obtain a concentration of $1 \mathrm{mg} / \mathrm{mL}$ and the plate was incubated for $45 \mathrm{~min}$ at $55^{\circ} \mathrm{C}$. Nlauryl sarcosine (Sarkosyl, Fisher Scientific) was added to obtain an $0.8 \%$ solution and pronase (Protease from Streptomyces griseus, Sigma-Aldrich, P5147) was added to obtain approximately $300 \mathrm{U} / \mathrm{mL}$ and the plate was incubated for $45 \mathrm{~min}$ at $55^{\circ} \mathrm{C}$. The contents of each well was removed and saved and $30 \mu \mathrm{L}$ of $10 \%$ SDS was added to each well and the solution was mixed by pipeting. The contents of each well was added back and the plate was incubated for $6 \mathrm{~h}$ at $55^{\circ} \mathrm{C}$. Subsequent to this step the manufacturer's instructions were followed to purify the DNA from the lysate beginning with the addition of $200 \mu \mathrm{L}$ of lysis solution C contained in the kit, vortexing for $15 \mathrm{~s}$ and incubation at $55^{\circ} \mathrm{C}$ for $15 \mathrm{~min}$. The final elution volume was $200 \mu \mathrm{L}$.

Quantitative PCR (qPCR) was used to quantify the DNA extracted from biofilms. Primers homologous to regions in the 16S RNA coding portion and specific for A. actinomycetemcomitans and S. sanguinis were designed with the NCBI primer designing tool (www.ncbi.nlm.nih.gov/tools/primer-blast/). Primers were CTC AGG ACG AAC GCT GGC GG (forward, Ss), ATC CCC CGC TAC CAG GCA GG (reverse, Ss), CCG GCT AAC TCC GTG CCA GC (forward, Aa), AGG TCC GCC TAC GTG CCC TT (reverse, Aa). Primers were designed explicitly to not crosshybridize with the non-targeted species and this was confirmed using conventional PCR and agarose gel electrophoresis. Quantification was performed by using a Rotor-gene $Q$ thermocycler (Qiagen) with a 15 min incubation period at $95^{\circ} \mathrm{C}$ followed by 50 cycles of amplification. Each cycle consisted of $15 \mathrm{~s}$ at $94^{\circ} \mathrm{C}, 30 \mathrm{~s}$ at $53^{\circ} \mathrm{C}$ and $30 \mathrm{~s}$ at $72{ }^{\circ} \mathrm{C}$. The $25 \mu \mathrm{L}$ reaction volumes contained $12.5 \mu \mathrm{L}$ SYBR Green ER qPCR SuperMix (Invitrogen), $5.5 \mu \mathrm{L}$ molecular biology grade water (Sigma-Aldrich, W4502), $1 \mu \mathrm{L}$ of $5 \mathrm{pmol} / \mu \mathrm{L}$ forward and reverse primers and $5 \mu \mathrm{L}$ of the sample. Threshold times determined from the fluorescence data curves were converted to DNA copy number based on standard curves generated from purified genomic DNA, quantified spectrophotometrically using a NanoDrop ND-100 spectrophotometer (Thermo Scientific). DNA copy number was converted to biofilm cell density (cells $/ \mathrm{cm}^{2}$ ) by multiplying by 40 to account for the $200 \mu \mathrm{L}$ elution volume, dividing by the number of $16 \mathrm{~S}$ copies in 

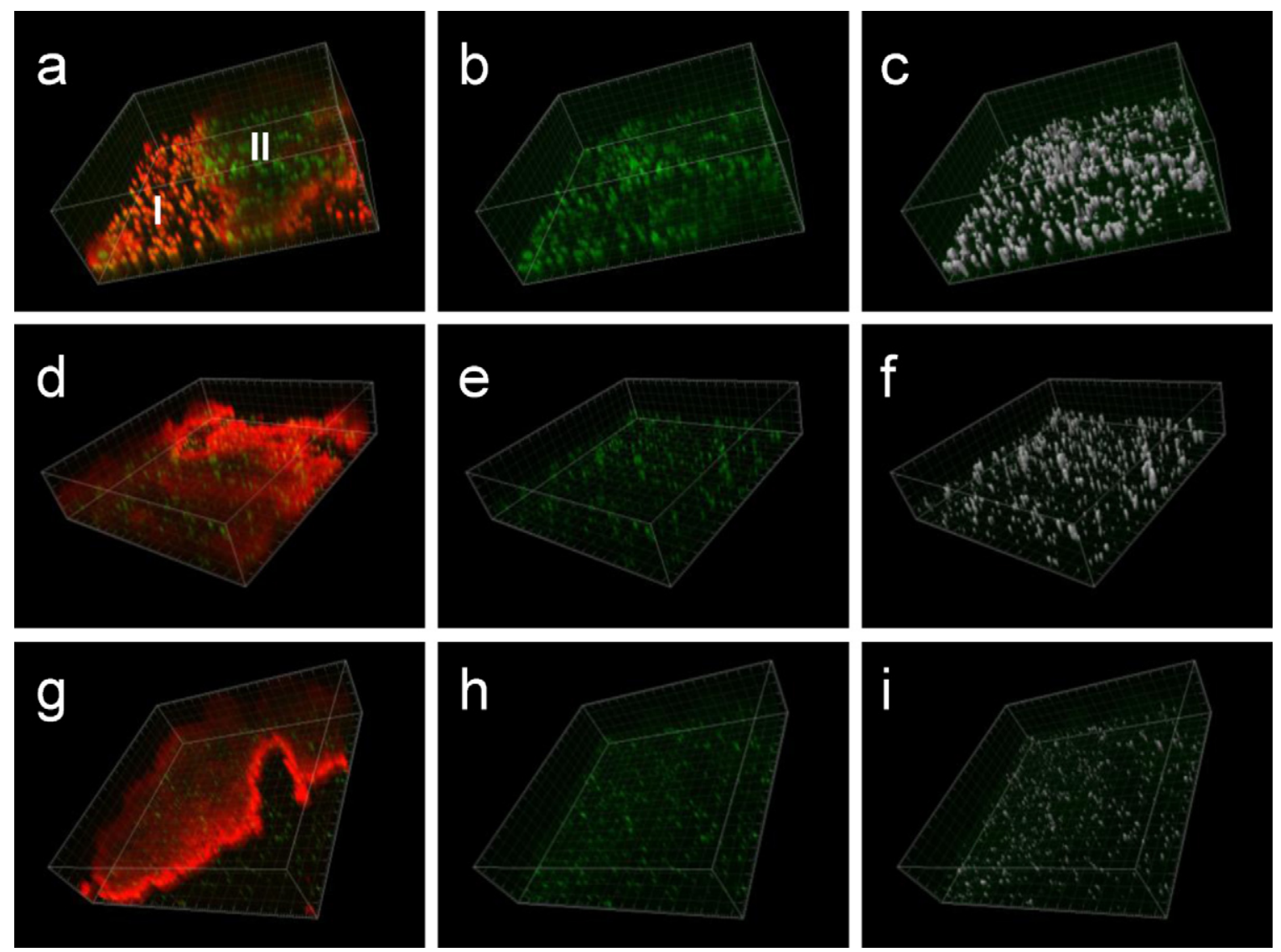

Fig. 1 - CLSM images of dual species biofilms. (a-c) No ciprofloxacin treatment; (d-f) $0.01 \mathrm{mg} / \mathrm{L}$ ciprofloxacin; (g-i) $0.5 \mathrm{mg} / \mathrm{L}$ ciprofloxacin. (a, d and g) (left column) Composites of the red and green fluorescence channels. (b, e and h) (middle column) Green channel (A. actinomycetemcomitans microcolonies). (c, $f$ and i) (right column) Surface representations of the green channel used to compute $A$. actinomycetemcomitans microcolony volumes. Tick marks are at $4 \mu \mathrm{m}$ spacings yielding a field size of $380 \mu \mathrm{m} \times 380 \mu \mathrm{m}$. Regions labelled I and II in (a) are discussed in the text.

the A. actinomycetemcomitans or S. sanguinis genome (6 and 4, respectively), and diving by 0.196 to account for the well area $\left(0.196 \mathrm{~cm}^{2}\right)$.

\subsection{Statistical analysis}

Statistical significance of differences in means was evaluated by an unpaired t test for three replicates of the experimental conditions being compared.

\section{Results}

\subsection{Selective killing visualized by confocal microscopy}

In dual species biofilms composed of the oral pathogen, A. actinomycetemcomitans and the oral commensal, S. sanguinis, A. actinomycetemcomitans formed discrete microcolonies on the surface that were overlaid in some portions with a lawn of $S$. sanguinis. Fig. 1 presents images of $48 \mathrm{~h}$ biofilms. Exposure to ciprofloxacin during the first $24 \mathrm{~h}$ of co-species biofilm development selectively inhibited the growth of A. actinomycetemcomitans biofilm as indicated by the reduced colony sizes in treated biofilms (Fig. 1d-i) compared to untreated biofilm
(Fig. 1a-c). Both species were stained with a red nucleic acid stain whilst A. actinomycetemcomitans was labelled with an A. actinomycetemcomitans-specific antibody coupled to a fluorescent secondary antibody, rendering the A. actinomycetemcomitans cells green. Regions of partial S. sanguinis biofilm coverage revealing the edge of the $S$. sanguinis lawn are shown. Images in the left column are composites of the red and green fluorescence channels whilst images in the middle column consist of only the green channel (A. actinomycetemcomitans microcolonies). In the right column are the surface representations of the green channel used to compute A. actinomycetemcomitans microcolony biovolumes. Biovolumes computed from these surface representations are 37.2, 8.22 and 3.01 in units of $10^{4} \mu \mathrm{m}^{3}$ for Fig. 1a, d and g, respectively. (Data for replicates are presented below). Untreated A. actinomycetemcomitans microcolonies appear green in the composite image in the region of Fig. 1a indicated by II, whereas colonies in the region not colonized with S. sanguinis (region I) appear red. Coverage by the S. sanguinis biofilm in region II was apparent when the field was observed through the ocular using epifluorescence, even though the red fluorescence in the confocal image is very faint. We propose that the green hue of the A. actinomycetemcomitans microcolonies in region II of Fig. 1a is due to an optical effect originating from attenuation of the red 

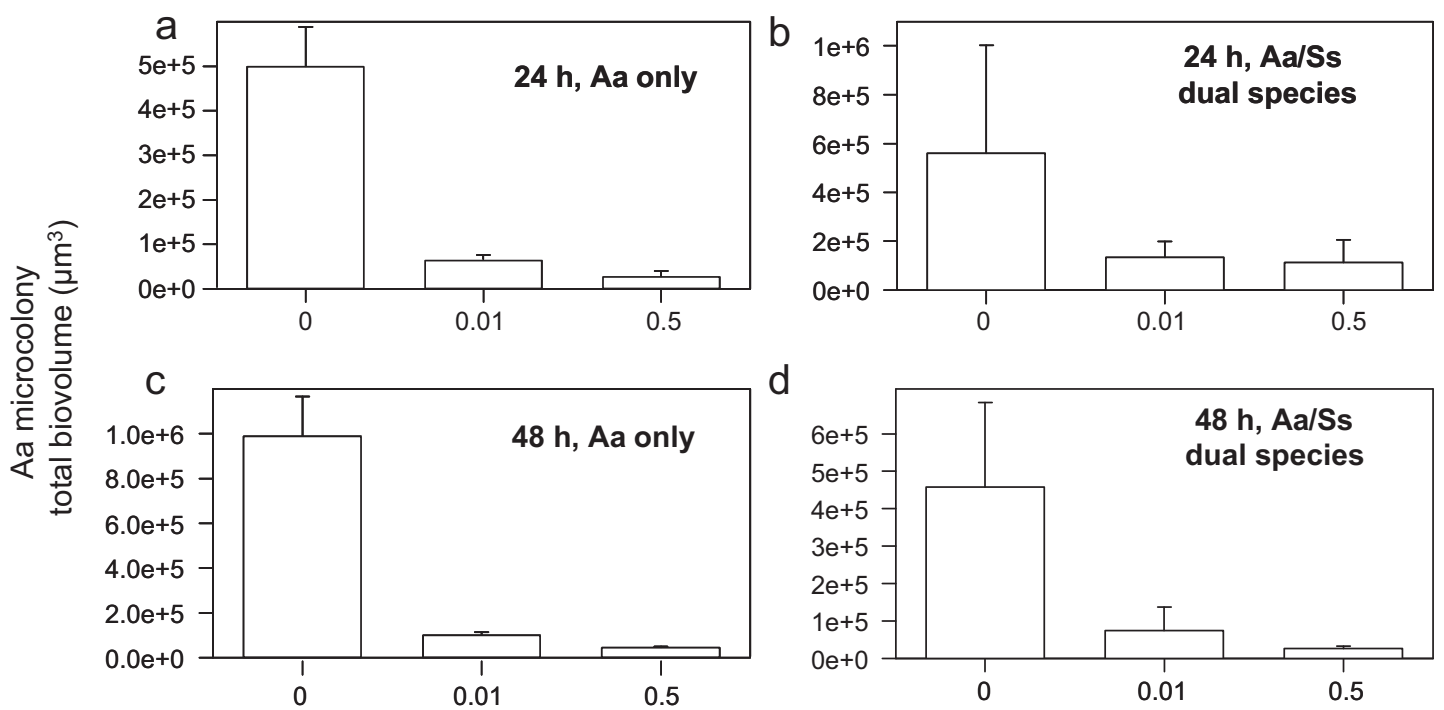

Ciprofloxacin concentration (mg/L)

Fig. 2 - A. actinomycetemcomitans microcolony biovolumes showing inhibition of A. actinomycetemcomitans over a $24 \mathrm{~h}$ period, and killing evidenced by lack of growth during a subsequent $24 \mathrm{~h}$ period after removal of ciprofloxacin. (a) Single species $24 \mathrm{~h}$ A. actinomycetemcomitans (Aa) biofilm; (b) Dual species $24 \mathrm{~h}$ A. actinomycetemcomitans/S. sanguinis (Aa/Ss) biofilm (c) Single species $48 \mathrm{~h}$ A. actinomycetemcomitans (Aa) biofilm (d) Dual species $48 \mathrm{~h}$ A. actinomycetemcomitans/S. sanguinis (Aa/Ss) biofilm. Data are total biovolume over the field of view $(380 \mu \mathrm{m} \times 380 \mu \mathrm{m})$. Error bars are standard deviations.

fluorescent signal by the relatively thick S. sanguinis biofilm. We observed that the treated A. actinomycetemcomitans microcolonies stained more faintly with the nucleic acid stain than the untreated colonies in single species biofilms (data not shown). We propose that this phenomenon allowed the green fluorescence from antibody-labelled A. actinomycetemcomitans microcolonies to dominate in the composite images of treated biofilms even in regions where they were not overlaid with a lawn of S. sanguinis biofilm (Fig. 1d and g, left column).

\subsection{Selective killing assessed by biovolume and biomass}

A. actinomycetemcomitans microcolony biovolumes computed from CLSM images show that exposure to 0.01 or $0.5 \mu \mathrm{m} / \mathrm{mL}$ ciprofloxacin for $24 \mathrm{~h}$ inhibited A. actinomycetemcomitans biofilm formation during development of both single and dual species biofilms (Fig. 2a and b). A. actinomycetemcomitans microcolonies in both single and dual species biofilms exhibited no increase in size during a subsequent $24 \mathrm{~h}$ period after removal of the ciprofloxacin indicating that A. actinomycetemcomitans cells were inactivated (Fig. 2c and d). Reported biovolumes are the means of the total A. actinomycetemcomitans microcolony volume per field of view. A. actinomycetemcomitans microcolony biovolumes for untreated $24 \mathrm{~h}$ and $48 \mathrm{~h}$ biofilms are all significantly different from those of treated biofilms at the 0.01 level of significance for all conditions (for both single and dual species biofilms). Compared to $24 \mathrm{~h}$ biofilms, A. actinomycetemcomitans microcolony size in dual species biofilms was actually reduced by 45 and $70 \%$ in $48 \mathrm{~h}$ biofilms treated with 0.01 and $0.5 \mathrm{mg} / \mathrm{L}$ ciprofloxacin, respectively. For the $0.5 \mathrm{mg} / \mathrm{L}$ treatment this reduction was significant at the 0.05 level ( $p$ value, 0.0216$)$
The CV assay is typically used as an index of biofilm biomass. ${ }^{28,32} \mathrm{CV}$ absorbance values indicate that $\mathrm{S}$. sanguinis biofilm formation was uninhibited by exposure to ciprofloxacin in the dual species biofilms (Fig. 3). A. actinomycetemcomitans biofilm microcolonies in the treated dual species biofilms are relatively small compared to the $S$. sanguinis lawn which is expected to dominate the biomass. The contribution of $\mathrm{A}$. actinomycetemcomitans biofilm microcolonies to the biomass in dual species biofilms was quantified by using the CV absorbance to biovolume ratio in untreated A. actinomycetemcomitans biofilm as a conversion factor. Using this factor to convert A. actinomycetemcomitans biovolumes, which were directly measured in single species biofilms (Fig. 2), to estimates of the percent contribution of the A. actinomycetemcomitans biofilm to the CV absorbance in the dual species biofilms yields 1.5 and $0.5 \%$ for biofilms treated with 0.5 and $0.01 \mathrm{mg} / \mathrm{L}$ ciprofloxacin, respectively. Accounting for this small contribution of A. actinomycetemcomitans biofilm to the biomass of dual species biofilms, differences between mean biomass of the untreated single species S. sanguinis biofilm and S. sanguinis biomass in both the treated dual species biofilms are insignificant ( $p$ values $>0.1$ ), both for the $24 \mathrm{~h}$ and $48 \mathrm{~h}$ time periods. In contrast to treated biofilms, A. actinomycetemcomitans biofilm made a significant contribution $(23.2 \%)$ to the biomass of the untreated dual species biofilm. Taking this contribution into account, the biomass of the S. sanguinis biofilm for the untreated condition was approximately $60 \%$ less in the dual species biofilm compared to the single species biofilm. This difference is significant at the 0.01 level. There is approximately a $20 \%$ reduction in S. sanguinis biomass in the $48 \mathrm{~h}$ treated single species biofilms compared to the $48 \mathrm{~h}$ untreated biofilm which are significant at the 0.01 level. 


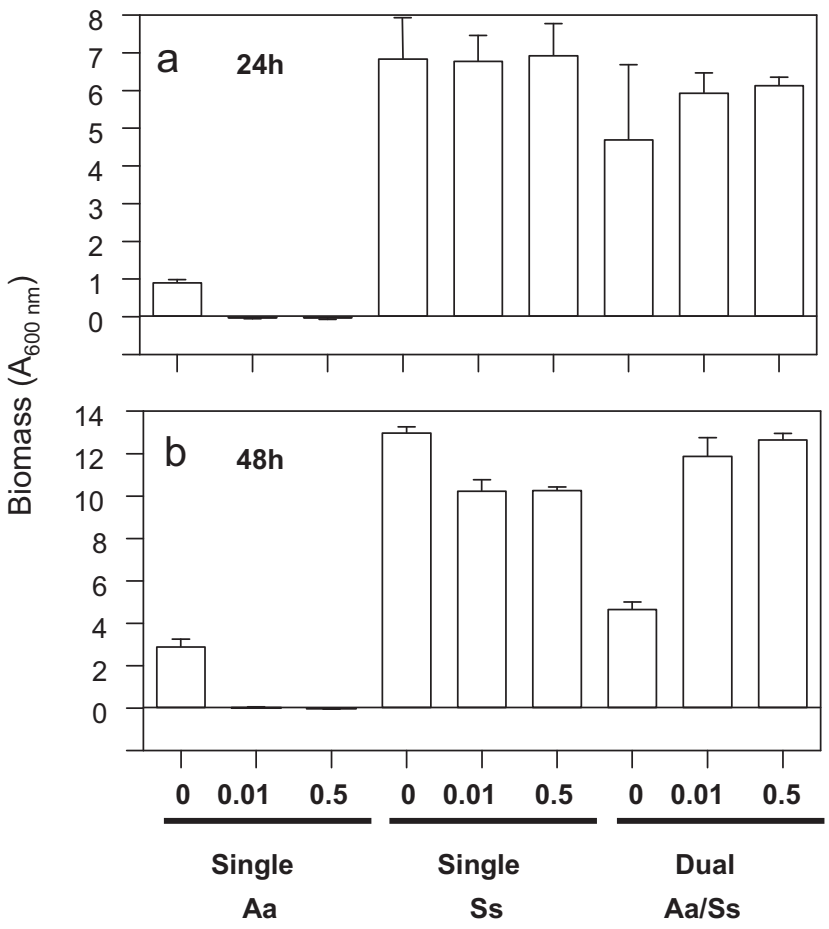

Fig. 3 - Quantification of biomass using CV indicating that S. sanguinis (Ss) biofilm development is uninhibited by ciprofloxacin at either the 0.01 or the $0.5 \mathrm{mg} / \mathrm{L}$ dose in the dual species biofilms. (a) $24 \mathrm{~h}$ biofilms; (b) $48 \mathrm{~h}$ biofilms. The graphs show the extent of $\mathrm{CV}$ staining $\left(A_{600} \mathrm{~nm}\right)$ versus various conditions. The contribution of $A$.

actinomycetemcomitans (Aa) to the biomass in the dual species A. actinomycetemcomitans/S. sanguinis (Aa/Ss) treated biofilms is less than $2 \%$ as discussed in the text. The lower biomass of the untreated dual species biofilm may be due to the influence of the underlying $A$. actinomycetemcomitans microcolonies on S. sanguinis biofilm formation or detachment. Absorbances were below background for three of the treated single species biofilms yielding negative values for the background subtracted data. Numbers on the abscissa refer to ciprofloxacin concentrations as in Fig. 2. Error bars are standard deviations.

\subsection{Selective killing assessed by DNA content}

According to qPCR data, exposure to ciprofloxacin for $24 \mathrm{~h}$ at both 0.01 and $0.5 \mathrm{mg} / \mathrm{L}$ reduced cell surface density of $\mathrm{A}$. actinomycetemcomitans in the dual species biofilm by more than two orders of magnitude compared to the untreated control (Fig. 4a). There was no increase in A. actinomycetemcomitans biofilm cell surface density during the $24 \mathrm{~h}$ period following removal of the ciprofloxacin indicating that A. actinomycetemcomitans biofilm had been inactivated (Fig. 4b). Differences in A. actinomycetemcomitans cell surface density for treated biofilm and biofilm treated with 0.01 and $0.5 \mathrm{mg} / \mathrm{L}$ ciprofloxacin are significant at the 0.05 level for both $24 \mathrm{~h}$ and $48 \mathrm{~h}$ biofilms. Similar to the biovolume data, there was actually a decrease in cell surface density over the $24 \mathrm{~h}$ period following

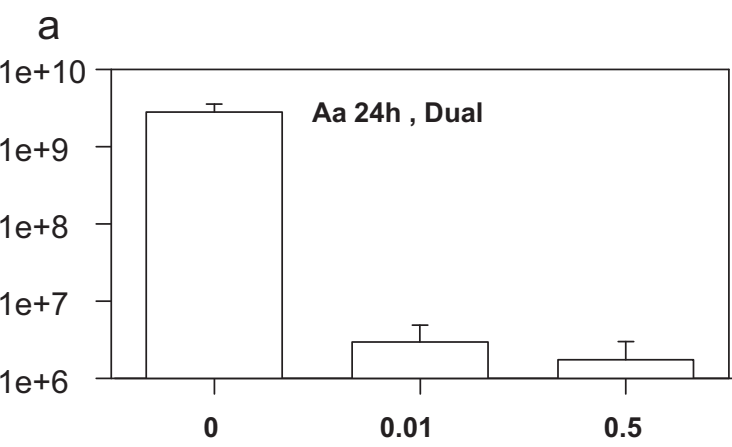

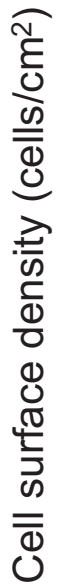

b

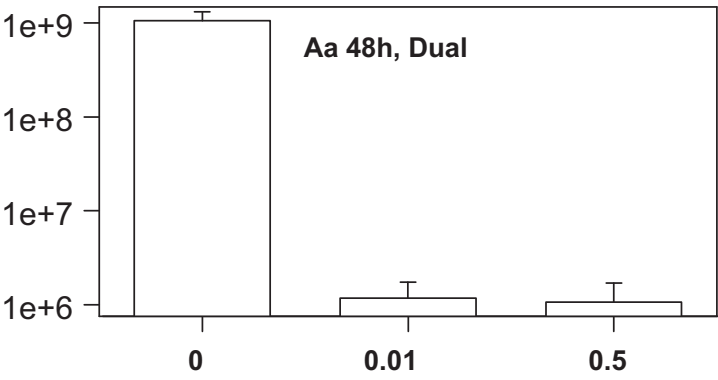

C

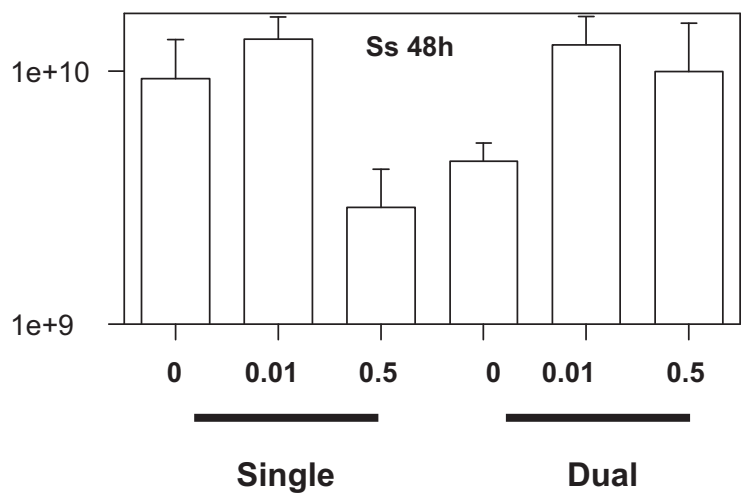

Fig. 4 - Cell surface densities assessed by qPCR showing selective killing of $\mathrm{A}$. actinomycetemcomitans (Aa) in the dual species biofilm. (a) A. actinomycetemcomitans (Aa) cell surface densities in the $24 \mathrm{~h}$ dual species biofilm; (b) $\mathrm{A}$. actinomycetemcomitans (Aa) cell surface densities in the $48 \mathrm{~h}$ dual species biofilm; (c) $\mathrm{S}$. sanguinis (Ss) cell surface densities in single and dual species $48 \mathrm{~h}$ biofilms. Numbers on the abscissa refer to ciprofloxacin concentrations as in Fig. 2. Error bars are standard errors.

removal of the ciprofloxacin of 60 and $39 \%$, for dual species biofilms treated with 0.01 and $0.5 \mathrm{mg} / \mathrm{L}$ ciprofloxacin, respectively; however, these reductions are not significant at the 0.05 level. S. sanguinis cell surface densities are between $2.8 \times 10^{9}$ and $1.3 \times 10^{10}$ cells $/ \mathrm{cm}^{2}$ in single and dual species biofilms, both treated and untreated with ciprofloxacin (Fig. 4c). Consistent with the biovolume data, the S. sanguinis cell surface density was lower for the untreated condition in the 
dual species biofilm. However, this reduction is not significant at the 0.05 level. The $S$. sanguinis cell surface density was also lower for the single species biofilm treated with $0.5 \mathrm{mg} / \mathrm{L}$, but means are not significantly different at the 0.05 level. Assuming that more replicates would increase the level of significance of this result, this is consistent with the biovolume data and may reflect an effect of the higher ciprofloxacin dose $(0.5 \mu \mathrm{m} / \mathrm{mL})$ on the $\mathrm{S}$. sanguinis biofilm which is mitigated in the dual species biofilm.

\section{Discussion}

In order to test the hypothesis that oral commensals contribute to reestablishment of immune homeostasis during treatment of periodontal disease methods that can be used in vivo to selectively eliminate pathogens are needed. The possibilities range from relatively sophisticated targeting approaches ${ }^{29,33,34}$ to general application of conventional antimicrobials which are known to have some selectivity. ${ }^{35}$ The complexity of possible factors influencing antimicrobial action against biofilms demands that the feasibility of proposed strategies be verified on in vitro biofilm models before moving to animal models or clinical trials. The dual species biofilm we developed could be exploited to probe the efficacy of both targeted and more generally selective (nontargeted) strategies.

Our results suggest that exposure of periodontal surfaces to ciprofloxacin could prevent establishment of a mature A. actinomycetemcomitans biofilm during a regrowth period following conventional treatment whilst allowing unhindered biofilm formation by the commensal, S. sanguinis. Periodontitis is treated initially by mechanical removal of plaque, with local or systemic application of antibiotics reserved for more recalcitrant cases. $^{36}$ We followed a ciprofloxacin dosing regime that can be attained by systemic application. ${ }^{37,38} \mathrm{~A}$. actinomycetemcomitans resistance to ciprofloxacin is rare, or perhaps non-existent. ${ }^{39}$ The lack of inhibition of S. sanguinis by the higher $(0.5 \mathrm{mg} / \mathrm{L})$ ciprofloxacin dose leaves an allowance margin for possible development of A. actinomycetemcomitans resistance. Although fluoroquinolones have been used to treat periodontitis, ${ }^{40,41}$ there has been no systematic study conducted to test whether selective elimination occurs in vivo and whether it improves the clinical outcome. Such studies may reveal that more sophisticated highly selective targeting approaches are essential to prevent detrimental shifts in the commensal population composition, or prevent selection of resistant pathogens.

Our strategy for selective killing was predicated on differential planktonic MICs for the pathogen and the commensal. One implication is that the greater efficacy of fluoroquinolones against gram-negative bacteria compared to gram-positive bacteria might be leveraged to selectively reduce the pathogen load in other forms of periodontitis. However, it cannot be assumed a priory that this relatively simple strategy will have general application since the biofilm mode of growth can profoundly alter the efficacy of antimicrobials, most commonly by conferring an intrinsic resistance. The key factor here may be that biofilms were exposed to the antimicrobial during the regrowth period. Most theories to explain biofilm resistance revolve around qualities that manifest as the biofilm matures. ${ }^{16,23,42}$

We anticipated that interspecies interactions would play a more obvious role in the dual species biofilm development. A. actinomycetemcomitans is able to utilise a metabolic byproduct of Streptococcal fermentation as a nutrient and hydrogen peroxide produced by Streptococci at subinhibitory levels is sensed by A. actinomycetemcomitans. ${ }^{27}$ Conversely, it was shown that A. actinomycetemcomitans produces a compound that is toxic to Streptococci. ${ }^{43}$ There are, in fact, hints of possible cospecies interactions in our data. S. sanguinis biofilm was less abundant in untreated dual species biofilms suggesting that A. actinomycetemcomitans biofilm might inhibit $S$. sanguinis biofilm formation or induce detachment. A. actinomycetemcomitans microcolony size was reduced in untreated dual species biofilms compared to untreated single species A. actinomycetemcomitans biofilms. The inhibition of A. actinomycetemcomitans by Streptococcal hydrogen peroxide could be responsible for this. However, a more obvious explanation would be nutrient limitation in the static system. The next logical step in pursuing in vitro studies is to use a flowing system which has the advantage of being more like the in vivo situation but with the disadvantage of being less high through-put.

The reduction in A. actinomycetemcomitans microcolony biovolume for treated versus untreated biofilm is less pronounced than the reduction in cell surface densities (Figs. 2 and 4). This could be a consequence of artefacts in either of the measurements. However, in support of the quality of the data, the correspondence between biovolumes and cell surface densities for untreated biofilm are reasonable. Specifically, the volume per cell based on the ratio of biovolume to cell surface density is approximately $0.35 \mu \mathrm{m}^{3}$, equivalent to a cube having dimensions of $0.7 \mu \mathrm{m}$ per side. A. actinomycetemcomitans cells are relatively small rods with dimensions less than $1 \mu \mathrm{m}^{44}$ and cells are fairly tightly packed in the biofilm microcolonies. ${ }^{45}$ Exposure of a susceptible strain of Escherichia coli (MIC $0.012 \mathrm{mg} / \mathrm{L}$ ) to $0.012 \mathrm{mg} / \mathrm{L}$ ciprofloxacin for 40 min induces DNA fragmentation followed by diffusion of the fragments outside the cell after a relatively mild lysis step. ${ }^{46}$ It seems possible that A. actinomycetemcomitans cell walls would become sufficiently permeable to allow diffusion of DNA fragments through the cell wall during a $24 \mathrm{~h}$ exposure period. This would be consistent with the reduced nucleic acid staining of treated A. actinomycetemcomitans microcolonies noted in Section 3, and would explain the discrepancy in relative reductions in biovolume and cell surface densities of the treated biofilms compared to untreated biofilms.

In summary, we have developed a relevant dual species biofilm model composed of a periodontal pathogen and an oral commensal and presented measurement techniques that enable its characterization. In addition, we demonstrated a relatively simple means of controlling the composition of the dual species consortium. From a general perspective, methods to manipulate biofilm consortia in situ provide tools for investigating the hypothesis that oral commensals play a critical role in maintenance of healthy immune function. The significance of testing this hypothesis lies not only in finding better approaches for clinical treatment of periodontal disease, but in understanding immune interactions with complex biofilm consortia. ${ }^{22}$ 
Conflict of interest: There is no conflict of interest.

Funding: This work was supported by NIH grant 1R21DE019237-01A1 to M.Y.

Ethical approval: Does not apply.

\section{RE F E RE N C E S}

1. Southerland JH, Taylor GW, Moss K, Beck JD, Offenbacher S. Commonality in chronic inflammatory diseases: periodontitis, diabetes, and coronary artery disease. Periodontology 2000, 2006;40:130-43.

2. Barnes PJ, Larin M. Mechanisms of disease - Nuclear factor $\kappa \mathrm{B}-\mathrm{A}$ pivotal transcription factor in chronic inflammatory diseases. New England Journal of Medicine 1997;336:1066-71.

3. Aloisi F, Pujol-Borrell R. Lymphoid neogenesis in chronic inflammatory diseases. Nature Reviews Immunology 2006;6:205-17.

4. Marton IJ, Kiss C. Protective and destructive immune reactions in apical periodontitis. Oral Microbiology and Immunology 2000;15:139-50.

5. Garlet GP, Cardoso CRB, Campanelli AP, Ferreira BR, AvilaCampos MJ, Cunha FQ et al. The dual role of p55 tumor necrosis factor- $\alpha$ receptor in Actinobacillus actinomycetemcomitans-induced experimental periodontitis: host protection and tissue destruction. Clinical and Experimental Immunology 2007;147:128-38.

6. Taubman MA, Valverde $P$, Han XZ, Kawai T. Immune response: the key to bone resorption in periodontal disease. Journal of Periodontology 2005;76:2033-41.

7. Trombone APF, Ferreira SB, Raimundo FM, de Moura KCR, Avila-Campos MJ, Silva JS, et al. Experimental periodontitis in mice selected for maximal or minimal inflammatory reactions: increased inflammatory immune responsiveness drives increased alveolar bone loss without enhancing the control of periodontal infection. Journal of Periodontal Research 2009;44:443-51.

8. Tlaskalova-Hogenova H, Stepankova R, Hudcovic T, Tuckova L, Cukrowska B, Lodinova-Zadnikova R, et al. Commensal bacteria (normal microflora), mucosal immunity and chronic inflammatory and autoimmune diseases. Immunology Letters 2004;93:97-108.

9. Neish AS, Gewirtz AT, Zeng H, Young AN, Hobert ME, Karmali V, et al. Prokaryotic regulation of epithelial responses by inhibition of I $\mathrm{\kappa B}$-alpha ubiquitination. Science 2000;289:1560-3.

10. Roberts FA, Darveau RP. Beneficial bacteria of the periodontium. Periodontology 2000, 2002;30: $40-50$.

11. Mombelli A, Samaranayake LP. Topical and systemic antibiotics in the management of periodontal diseases. International Dental Journal 2004;54:3-14.

12. Chino T, Santer DM, Giordano D, Chen C, Li C, Chen CH, et al. Effects of oral commensal and pathogenic bacteria on human dendritic cells. Oral Microbiology and Immunology 2009;24:96-103.

13. Beklen A, Sorsa T, Konttinen YT. Toll-like receptors 2 and 5 in human gingival epithelial cells co-operate with T-cell cytokine interleukin-17. Oral Microbiology and Immunology 2009;24:38-42.

14. Listgarten MA. Pathogenesis of periodontitis. Journal of Clinical Periodontology 1986;13:418-25.

15. Tanner A, Kent R, Maiden MFJ, Taubman MA. Clinical, microbiological and immunological profile of healthy, gingivitis and putative active periodontal subjects. Journal of Periodontal Research 1996;31:195-204.
16. Socransky SS, Haffajee AD. Dental biofilms: difficult therapeutic targets. Periodontology 2000, 2002;28:12-55.

17. Avery RK. Adding gram-positive prophylaxis to fluoroquinolone regimens reduces streptococcal bacteraemias, but prophylaxis remains controversial. Cancer Treatment Reviews 2004;30:385-8.

18. Appelbaum PC, Hunter PA. The fluoroquinolone antibacterials: past, present and future perspectives. International Journal of Antimicrobial Agents 2000;16:5-15.

19. Hoogkamp-Korstanje JAA, Roelofs-Willemse J. Comparative in vitro activity of moxifloxacin against gram-positive clinical isolates. Journal of Antimicrobial Chemotherapy 2000;45:31-9.

20. Muller HP, Holderrieth S, Burkhardt U, Hoffler U. In vitro antimicrobial susceptibility of oral strains of Actinobacillus actinomycetemcomitans to seven antibiotics. Journal of Clinical Periodontology 2002;29:736-42.

21. Fine DH, Kaplan JB, Kachlany SC, Schreiner HC. How we got attached to Actinobacillus actinomycetemcomitans: a model for infectious diseases. Periodontology 2000, 2006;42:114-57.

22. Henderson B, Nair SP, Ward JM, Wilson M. Molecular pathogenicity of the oral opportunistic pathogen Actinobacillus actinomycetemcomitans. Annual Review of Microbiology 2003;57:29-55.

23. Stewart PS, Costerton JW. Antibiotic resistance of bacteria in biofilms. Lancet 2001;358:135-8.

24. Kuboniwa M, Tribble GD, James CE, Kilic AO, Tao L, Herzberg $\mathrm{MC}$, et al. Streptococcus gordonii utilizes several distinct gene functions to recruit Porphyromonas gingivalis into a mixed community. Molecular Microbiology 2006;60:121-39.

25. Filoche SK, Zhu M, Wu CD. In situ biofilm formation by multi-species oral bacteria under flowing and anaerobic conditions. Journal of Dental Research 2004;83:802-6.

26. Periasamy S, Kolenbrander PE. Aggregatibacter actinomycetemcomitans builds mutualistic biofilm communities with Fusobacterium nucleatum and Veillonella species in saliva. Infection and Immunity 2009;77:3542-51.

27. Ramsey MM, Whiteley M. Polymicrobial interactions stimulate resistance to host innate immunity through metabolite perception. Proceedings of the National Academy of Sciences of the United States of America 2009;106:1578-83.

28. Ge XC, Kitten T, Chen ZM, Lee SP, Munro CL, Xu P. Identification of Streptococcus sanguinis genes required for biofilm formation and examination of their role in endocarditis virulence. Infection and Immunity 2008;76:2551-9.

29. Suci P, Kang S, Gmur R, Douglas T, Young M. Targeted delivery of a photosensitizer to Aggregatibacter actinomycetemcomitans biofilm. Antimicrobial Agents and Chemotherapy 2010;54:2489-96.

30. Gmür R, Thurnheer T. Monoclonal antibodies for the rapid identification in clinical samples of Peptostreptococcus micros and Actinobacillus actinomycetemcomitans serotypes, a, d, and e. Medical Microbiology Letters 1996;5:335-49.

31. Ganeshkumar N, Song M, McBride BC. Cloning of a Streptococcus sanguis adhesin which mediates binding to saliva-coated hydroxyapatite. Infection and Immunity 1988;56:1150-7.

32. Flemming K, Klingenberg C, Cavanagh JP, Sletteng M, Stensen W, Svendsen JS, et al. High in vitro antimicrobial activity of synthetic antimicrobial peptidomimetics against staphylococcal biofilms. Journal of Antimicrobial Chemotherapy 2009;63:136-45.

33. Robinson AM, Creeth JE, Jones MN. The use of immunoliposomes for specific delivery of antimicrobial agents to oral bacteria immobilized on polystyrene. Journal of Biomaterials Science-Polymer Edition 2000;11:1381-93.

34. Embleton ML, Nair SP, Heywood W, Menon DC, Cookson BD, Wilson M. Development of a novel targeting system for lethal photo sensitization of antibiotic-resistant strains of 
Staphylococcus aureus. Antimicrobial Agents and Chemotherapy 2005;49:3690-6.

35. Beikler T, Prior K, Ehmke B, Flemmig TF. Specific antibiotics in the treatment of periodontitis-a proposed strategy. Journal of Periodontology 2004;75:169-75.

36. Greenstein G. Nonsurgical periodontal therapy in 2000: a literature review. Journal of the American Dental Association 2000;131:1580-92.

37. Conway TB, Beck FM, Walters JD. Gingival fluid ciprofloxacin levels at healthy and inflamed human periodontal sites. Journal of Periodontology 2000;71:1448-52.

38. Tozum TF, Yildirim A, Caglayan F, Dincel A, Bozkurt A. Serum and gingival crevicular fluid levels of ciprofloxacin in patients with periodontitis. Journal of the American Dental Association 2004;135:1728-32.

39. Madinier IM, Fosse TB, Hitzig C, Charbit Y, Hannoun LR. Resistance profile survey of 50 periodontal strains of Actinobacillus actinomycetemcomitans. Journal of Periodontology 1999;70:888-92.

40. Guentsch A, Jentsch H, Pfister W, Hoffmann T, Eico S. Moxifloxacin as an adjunctive antibiotic in the treatment of severe chronic periodontitis. Journal of Periodontology 2008;79:1894-903.
41. Kleinfelder JW, Mueller RF, Lange DE. Fluoroquinolones in the treatment of Actinobacillus actinomycetemcomitans associated periodontitis. Journal of Periodontology 2000;71:202-8

42. Takahashi N, Ishihara K, Kato T, Okuda K. Susceptibility of Actinobacillus actinomycetemcomitans to six antibiotics decreases as biofilm matures. Journal of Antimicrobial Chemotherapy 2007;59:59-65.

43. Hammond BF, Lillard SE, Stevens RH. A Bacteriocin of Actinobacillus actinomycetemcomitans. Infection and Immunity 1987;55:686-91.

44. Rhodes ER, Shoemaker CJ, Menke SM, Edelmann RE, Actis LA. Evaluation of different iron sources and their influence in biofilm formation by the dental pathogen Actinobacillus actinomycetemcomitans. Journal of Medical Microbiology 2007;56:119-28.

45. Kaplan JB, Meyenhofer MF, Fine DH. Biofilm growth and detachment of Actinobacillus actinomycetemcomitans. Journal of Bacteriology 2003;185:1399-404.

46. Tamayo M, Santiso R, Gosalvez J, Bou G, Fernandez JL. Rapid assessment of the effect of ciprofloxacin on chromosomal DNA from Escherichia coli using an in situ DNA fragmentation assay. BMC Microbiology 2009:9. 